\title{
Small-Angle X-ray Scattering of Heat-Treated Flame-Fused Silica Glass from Amorphous and Crystalline Powders
}

\author{
A. H. Shinohara, ${ }^{a}$ K. OMOte, ${ }^{b}$ E. H. SeKIYA, ${ }^{a}$ K. ShInOda, ${ }^{c}$ D. TORIKAI, ${ }^{a}$ C. K. SUZUKI ${ }^{a}$ \\ AND C. A. C. ZAVAGLIA ${ }^{a}$ \\ ${ }^{a}$ Materials Engineering Department, Faculty of Mechanical Engineering, University of Campinas CP 6122, \\ Campinas-SP, Brazil, ${ }^{b}$ Rigaku Corporation, Akishima, Tokyo 196, Japan, and ${ }^{c}$ Institute for Advanced Materials \\ Processing, Tohoku University, Sendai 981, Japan.E-mail: hideki@fem.unicamp.br
}

(Received 14 February 1997; accepted 21 February 1997)

\begin{abstract}
High-quality as-fused silica glass, heat treated at $1523 \mathrm{~K}$ and prepared by the flame-fusion process using natural crystalline quartz and high-purity amorphous silica glass powders, was investigated by small-angle X-ray scattering (SAXS). The X-ray scattering intensity amplitude from the amorphous structure after heat treatment was analysed in terms of viscosity, density and metallic impurity content. It is shown that SAXS scattering of the amorphous sample is sensitive to the structural change induced by annealing.
\end{abstract}

\section{Introduction}

High-quality silica glass was obtained by the flamefusion technique using crystalline natural quartz and high-purity sol-gel silica powers. (Torikai et al., 1994). In a recent investigation of amorphous and crystalline powders by the small-angle X-ray scattering (SAXS) technique, an appreciable SAXS intensity was observed for the amorphous powder. The fundamental properties of glass such as viscosity and density have been measured and correlated with the hydroxyl content of the silica glass structure (Shackelford, Masaryk \& Fulrath, 1970; Torikai et al., 1994; Sekiya et al., 1996). It is also known that such physical properties depend mainly on their short- and medium-range structure (Brückner, 1970, 1971). Many studies of the short- and mediumrange-order structures of silica glass have been conducted by X-ray diffraction and spectroscopic techniques (Zarzycki, 1982; Mikkelsen \& Galeener, 1980; Geissberger \& Galeener, 1983; Gerber \& Himmel, 1986, 1987; Walter, Kranold, Göcke \& Enenkel, 1991; Wright, 1994; Elliott, 1995). The annealing effect on silica glass is quite sensitive to the content of impurities and defects. This is especially relevant to the optical-fibre-pulling process.

In the present work, structural changes induced by the annealing of silica glass samples prepared using crys- talline and amorphous powders were investigated by SAXS.

\section{Experimental procedure}

The flame-fused silica glass ingots were prepared by the Verneuil technique with a hydrogen/oxygen flame (Torikai et al., 1994) using two kinds of powders: (i) silica glass powder from pure tetramethoxysilane process-made by the Mitsubishi Kasei Corporation (hereafter referred to as amorphous powder); and (ii) natural quartz processed by Toshiba Ceramics Co. (hereafter referred to as crystalline powder). The main characteristics of the powders used in the present investigation are summarized in Table 1. The fusion temperature was measured at about $1973 \mathrm{~K}$ by an optical pyrometer without correcting for the emissivity factor. As-fused ingots of silica glass were sliced with a diamond saw to give samples $30 \mathrm{~mm}$ long, $5 \mathrm{~mm}$ wide and $2 \mathrm{~mm}$ thick which were polished with $\mathrm{SiC}$ powders of 320,800 , 1500 and 4000 mesh. Three samples were prepared from each ingot. Heat treatment was conducted at $1523 \mathrm{~K}$ for $15 \mathrm{~min}$ in an electric furnace in air. The samples were put on a plate of silica glass to avoid direct contact with insulator bricks. The heating rate was $10 \mathrm{~K} \mathrm{~min}^{-1}$ and after heat treatment the electric furnace was turned off. In order to investigate only the structural changes induced in the amorphous phase of silica glass by annealing, crystallized surfaces were removed by polishing and the thickness of the sample adjusted to $1.2 \mathrm{~mm}$ to have $\mu t \sim 1$ ( $\mu$ is the linear absorption coefficient and $t$ is the sample thickness) for Mo $K \alpha$ radiation. The sample surface was polished with $\mathrm{SiC}$ powder of 1500 mesh to remove any recrystallized surface, checking a total suppression of the main peak (101) of $\alpha$ cristobalite.

SAXS measurements were conducted in transmission mode with $M o K \alpha_{1}$ radiation monochromatized with a channel-cut $\mathrm{Ge}(220)$ monochromator. A rotating anode with $50 \mathrm{kV}$ and $270 \mathrm{~mA}$ was used as the X-ray source. 
Table 1. Characteristics of powder and silica glass ingot

Type of powder and average grain size

Amorphous powder $\sim 400 \mu \mathrm{m}$

Crystalline powder $\sim 760 \mu \mathrm{m}$

\begin{tabular}{|c|c|}
\hline \multicolumn{2}{|c|}{ Powder } \\
\hline $\begin{array}{l}\text { Total metallic } \\
\text { impurity content }\end{array}$ & $\begin{array}{c}{[\mathrm{OH}] \text { content }} \\
\text { in powder }\end{array}$ \\
\hline$\sim 100$ p.p.b. & 120 p.p.m. \\
\hline$\sim 37$ p.p.m. & not detected \\
\hline
\end{tabular}

The linear position-sensitive proportional counter detector (10 cm long PSPC-10, Rigaku Corporation) filled with Xe gas was used to detect the X-ray scattering in the range of wavenumber vector $Q=0.3-16 \mathrm{~nm}^{-9}$ $(|\mathbf{Q}|=4 \pi \sin \theta / \lambda$, where $2 \theta$ is the scattering angle and $\lambda$ is the $\mathrm{X}$-ray radiation wavelength). The $\mathrm{X}$-ray scattering data were collected with a multiple-channel analyser. SAXS data were corrected for background and sample absorption. To convert the observed SAXS intensity scattered by the as-fused and heat-treated silica glass samples into absolute units (electron units), the SAXS intensity $I(0)$ of water was used (Hayashi, Nishikawa \& lijima, (1989).

\section{Results and discussion}

The viscosity, density and hydroxyl content in the asfused ingots prepared with amorphous and crystalline powders are summarized in Table 1. It is worth mentioning that the total metallic impurity content measured in the powders remained almost the same after fusion into ingots. However, the hydroxyl content increased by the order of 100 p.p.m. The amount of hydroxyl aggregated into silica glass by the Verneuil process depends on the type of flame and powders used to obtain the ingots (Torikai et al., 1994).

Fig. 1 shows the X-ray scattering spectra of as-fused and heat-treated (for $15 \mathrm{~min}$ ) silica glass samples obtained from amorphous (Fig. $1 a$ ) and crystalline (Fig. $1 b)$ powders. The inset figures show in more detail the changes in SAXS scattering intensity after heat treatment. X-ray scattering from heat-treated silica glass is lower than that from the as-fused glass. This effect can be attributed to the decrease in the density fluctuation in the structure of silica glass. In particular, the zero-angle scattering obtained by extrapolation of the experimental data represents a measure of the magnitude of the density fluctuation in silica glass frozen-in during glass transition (Walter et al., 1991). The estimated values of zero-angle scattering intensity are shown in Table 2. However, the intensity amplitude of the main peak at $\mathbf{Q}=15 \mathrm{~nm}^{-1}$ increased with heat treatment. Considering the dense random packing of hard spheres, the realspace structural correlation length $r_{l}$ of the principal peak position, expressed approximately by $r_{l} \sim 7.7 / \mathbf{Q}_{p}$ (Salmon, 1994; Bletry, 1978), can be estimated as $r_{l}=0.5 \mathrm{~nm}$. A sharp diffraction peak corresponding to the (101) plane of $\alpha$-cristobalite appears close to the main peak at $\mathbf{Q}=15 \mathrm{~nm}^{-1}$ of silica glass when recrystallization takes place. Thus, the increase in the intensity amplitude of the main peak after heat treatment can be attributed to some ordering in the network units of $\mathrm{SiO}_{4}$ tetrahedra occurring at distance $r_{l}$.

Furthermore, a difference in the amplitude of X-ray scattering intensity spectra was observed between asfused and heat-treated silica glass samples prepared from amorphous and crystalline powders. Such a difference in X-ray scattering is discussed in terms of variation in viscosity and density and the impurity content. Fig. 2 shows a comparison of the X-ray scattering intensity spectra of heat-treated (at $1523 \mathrm{~K}$ for $15 \mathrm{~min}$ ) samples of silica glass prepared with amorphous and crystalline powders. Although the X-ray scattering

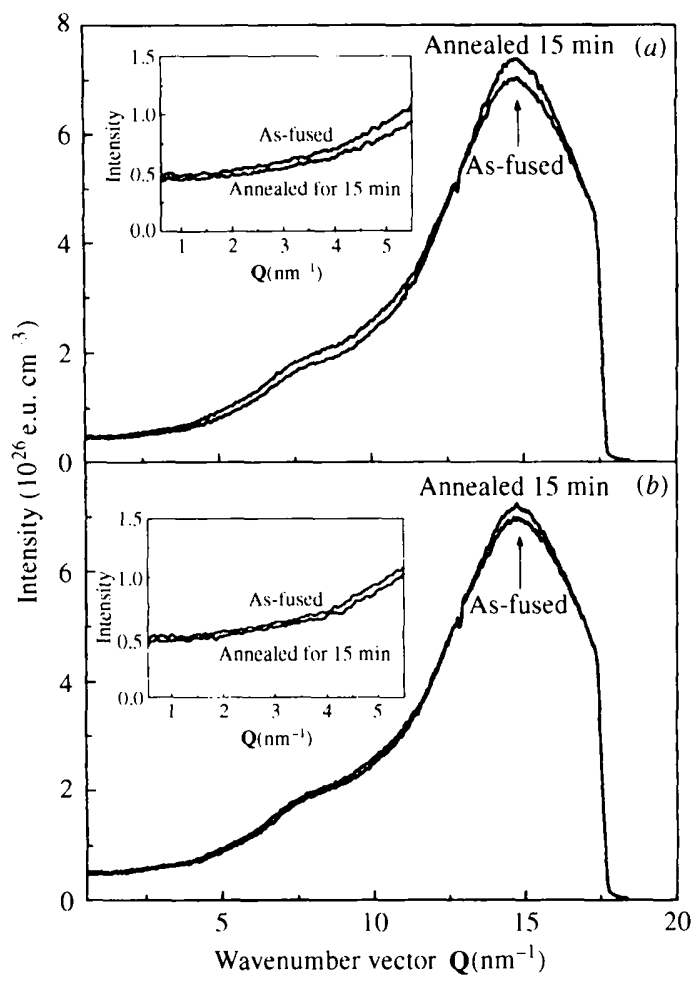

Fig. 1. X-ray scattering of as-fused and heat-treated $(1523 \mathrm{~K}$ for $15 \mathrm{~min}$ ) of silica glass prepared with $(a)$ amorphous powder and $(b)$ crystalline powder. The inset is a zoom of the SAXS scattering of $\mathbf{Q} \sim 0.5-5 \mathrm{~nm}$ ! 
Table 2. Zero-angle scattering of as-fused and heattreated samples

AMP, silica glass prepared from amorphous powder; CRP, silica glass prepared from crystalline powder.

\begin{tabular}{|c|c|c|}
\hline \multirow[t]{2}{*}{ Sample } & \multicolumn{2}{|c|}{$I(0)\left(10^{26}\right.$ e.u. $\left.\mathrm{cm}^{-3}\right)$} \\
\hline & As-fused & Heat-treated \\
\hline AMP & 0.488 & 0.454 \\
\hline CRP & 0.490 & 0.472 \\
\hline
\end{tabular}

intensity spectra from as-fused silica glass samples are quite similar, a significant difference can clearly be observed after heat treatment conducted under the same conditions. The inset figure shows that the SAXS scattering intensity from heat-treated silica glass from amorphous powder was lower than that from silica glass prepared from crystalline powder. However, the scattering intensity amplitude of the main peak of silica glass at $\mathbf{Q}=15 \mathrm{~nm}^{-1}$ appeared higher for silica glass obtained from amorphous powder. Based on the density values shown in Table 1 , silica glass prepared from amorphous powder has more voids (defects), although the total impurity content is almost three orders of magnitude lower than silica glass prepared from crystalline powder. Thus, it is believed that voids in the structure of silica glass facilitate the forming of a network of $\mathrm{SiO}_{4}$ tetrahedra, to attain a certain degree of ordering; at a correlation length of $0.5 \mathrm{~nm}$ this ordering takes place more quickly after heat treatment. Concerning the SAXS region, the higher metallic impurity content and viscosity of the structure of silica glass obtained from crystalline powder prevented a decrease in the density fluctuation. That is why the scattering intensity from silica glass prepared from crystalline powder remained higher in the SAXS region.

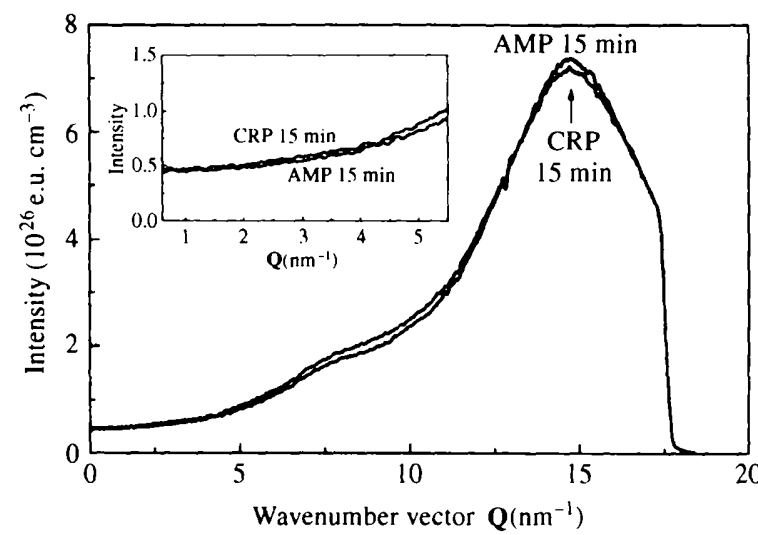

Fig. 2. A comparison of X-ray scattering intensity spectra from silica glass heat treated at $1523 \mathrm{~K}$ for $15 \mathrm{~min}$ produced using crystalline natural quartz (CRP) and amorphous powder (AMP).

\section{Concluding remarks}

Silica glass samples prepared from amorphous and crystalline powders were heat treated at $1523 \mathrm{~K}$ for $15 \mathrm{~min}$. The amorphous phase of as-fused and heattreated samples was investigated by SAXS. The following conclusions are drawn. The density fluctuation in the structure decreased with heat treatment; however, higher metallic impurity content and viscosity prevented this decrease. On the other hand, an additional analysis of the change in intensity amplitude at the main peak of silica glass, $\mathbf{Q}=15 \mathrm{~nm}^{-1}$, reveals that defects such as voids in the structure of silica glass probably facilitate ordering of a network formed of $\mathrm{SiO}_{4}$ tetrahedra at a correlation length $r_{l}=0.5 \mathrm{~nm}$ after heat treatment.

Additional investigations are being conducted so that a better understanding may be achieved of the effects of heat treatment and annealing time on the structure of silica glass prepared using different types of powders and deposition processes.

The authors are grateful to Professor Y. Waseda, Tohoku University, for use of the SAXS facility. They also thank Ms D. Y. Ogata and M. S. Zolotar for their help in preparing silica glass samples for SAXS measurement. This work received partial financial support from $\mathrm{CNPq}$ (Conselho Nacional de Desenvolvimento Científico e Tecnológico) and FAPESP (Fundação de Amparo à Pesquisa do Estado de São Paulo).

\section{References}

Bletry, J. (1978). Z. Naturforsch. Teil A, 33, 327-343.

Brückner, R. (1970). J. Non-Cryst. Solids, 5, 123-175.

Brückner, R. (1971). J. Non-Cryst. Solids, 5, 177-216.

Elliott, S. R. (1995). J. Non-Cryst. Solids, 182, 40-48.

Geissberger, A. E. \& Galeener, F. L. (1983). Phys. Rev. B, 28, 3266-3271.

Gerber, Th. \& Himmel, B. (1986). J. Non-Cryst. Solids, 83, 324-334.

Gerber, Th. \& Himmel, B. (1987). J. Non-Cryst. Solids, 92, 407-417.

Hayashi, H., Nishikawa, K. \& Iijima, T. (1989). Jpn J. Appl. Phys. 28, 1501-1503.

Mikkelsen, J. C. Jr \& Galeener, F. L. (1980). J. Non-Cryst. Solids, 37, 71-84.

Salmon, P. S. (1994). Proc. R. Soc. London Ser. A, 445, 351365.

Sekiya, E. H., Ogata, D. U., Torikai, D., Shinohara, A. H., Shimizu, H. \& Suzuki, C. K. (1996). Ceramica, 42, 685688.

Shackelford, J. F., Masaryk, J. S. \& Fulrath, R. M. (1970). J. Am. Ceram. Soc. 53, 417.

Torikai, D., Suzuki, C. K., Shimizu, H., Ishizuka, Y., Yagi, J., Orii, K. \& Miyazaka, T. (1994). J. Non-Cryst. Solids, 179, 328-334.

Walter, G., Kranold, R., Göcke, W. \& Enenkel, N. (1991). J. Appl. Cryst. 24, 616-623.

Wright, A. C. (1994). J. Non-Cryst. Solids, 179, 84-115.

Zarzycki, J. (1982). J. Non-Cryst. Solids, 52, 31-43. 